\title{
Nueva antropología filosófica La idea de ser humano en las ontologías de Markus Gabriel y Quentin Meillassoux
}

\section{New philsophical anthropology The idea of the human being in the ontologies of Markus Gabriel and Quentin Meillassoux}

\author{
MARIO TEODORO RAMÍREZ COBIÁN \\ Universidad Michoacana de San Nicolás de Hidalgo (México)
}

Recibido: 23/04/2020Ａceptado:11/12/2020

\begin{abstract}
RESUMEN
En este ensayo planteo la posibilidad de una renovación de la antropología filosófica desde la perspectiva ontológica del nuevo realismo, particularmente desde las teorías filosóficas de Markus Gabriel y Quentin Meillassoux. Previamente expongo la discusión sobre la antropología filosófica que se produjo en el siglo pasado, especialmente las disputas entre Ernst Cassirer y Martin Heidegger y entre Heidegger y Jean-Paul Sartre. Doy cuenta también de las líneas principales de la corriente filosófica del «nuevo realismo». Concluyo con la propuesta de una redefinición ontológica de ser humano, apuntando a la idea de un nuevo humanismo.
\end{abstract}

PALABRAS CLAVE

SER HUMANO, HUMANISMO, ESPÍRITU, LIBERTAD, CASSIRER, HEIDEGGER, LATOUR, HARMAN

\section{ABSTRACT}

In this essay I raise the possibility of a renewal of philosophical anthropology from the ontological perspective of the new realism, particularly from the philosophical theories of Markus Gabriel and Quentin Meillassoux. I previously set out the discussion on philosophical anthropology that occurred in the last century, especially the disputes between Ernst Cassirer and Martin Heidegger and between Heidegger and Jean-Paul Sartre. I also give an account of 
the main lines of the philosophical current of the «new realism». I conclude with the proposal of an ontological redefinition of the human being, pointing to the idea of a new humanism.

KEYWORDS

HUMAN BEING, HUMANISM, SPIRIT, FREEDOM, CASSIRER, HEIDEGGER, LATOUR, HARMAN

LA PRIMACÍA DE LA ONTOLOGÍA que propone la corriente filosófica del nuevo realismo ${ }^{1}$ conlleva la crítica del antropocentrismo y el humanismo de la filosofía moderna. No obstante, esto no significa que el tema de la realidad humana -de lo que es o debe ser el ser humano- se encuentre desatendida por los filósofos de esta corriente, al menos no por todas sus figuras representativas. Si bien la línea de lo que se ha llamado ontología plana (Levi Bryant, Graham Harman, Manuel DeLanda, Bruno Latour ${ }^{2}$ ) no acepta ninguna distinción relevante entre el ser humano y el resto de los entes, Quentin Meillassoux y Markus Gabriel, con perspectivas filosóficas muy distintas (Ramírez 2016), coinciden sin embargo en que no rehúyen ofrecer un concepto de lo propio del ser humano, aun concordando con la crítica al antropocentrismo. Suponemos que, como buenos filósofos, consideran que sería una ingenuidad asumir que un pensamiento acerca de la realidad -una ontología- puede obviar la pregunta por quién es el sujeto que piensa o cuál es la consistencia de ese pensamiento, qué es el ser humano -o qué no es, al menos-, aunque eso no signifique seguirlo considerando, como en la filosofía moderna, el centro o referente de

1 Por comodidad utilizo la expresión «nuevo realismo» para referirme a diversas corrientes de realismo surgidas en el siglo XXI en la llamada filosofía continental (es decir, la filosofía no analítica): el «materialismo especulativo» de Quentin Meillassoux, tal como lo formuló desde su tesis de doctorado de 1996; el «realismo especulativo», nombre surgido en el Coloquio de Londres de 2008, en el que participaron el propio Meillassoux, Graham Harman, Ray Brassier y Iain Hamilton Grant; una variante del realismo especulativo es la ontología orientada a objetos (OOO) de Harman. Al inicio de su libro de 2012 Manifiesto del nuevo realismo, con su humor característico, Maurizio Ferraris relata un encuentro con Markus Gabriel en un Café de Nápoles y que a las 13:30 del 23 de junio de 2011 ambos acordaron llamar New Realism al nuevo movimiento, en cuyos postulados coincidían (Ferraris 2013, p. 35). Actualmente existe un gran número de autores que suscriben alguna forma del nuevo realismo, como Levi R. Bryant, Steven Shaviro, Tom Sparrow, Catharine Malabou, Jane Bennett, Tristan Garcia, Jocelyn Benoist, María-José Binetti.

2 De manera general, porque no todos estos autores coinciden con la expresión de ontología plana, atribuida a Levi Bryant, aunque coinciden en una visión ontológica horizontal, no jerárquica. Cf. Latour 2008; Harman 2016; DeLanda 2010; Levi-Bryant 2011. Para la crítica a la ontología plana, cf. Brassier 2018. 
las cuestiones filosóficas básicas -ontológicas y epistemológicas. Observamos que la manera como ellos han afrontado la cuestión de la realidad humana resulta original e importante en función de las condiciones de nuestro siglo, particularmente frente al nihilismo prevaleciente que asume sin más que la existencia humana, y la existencia en general, no tiene ningún sentido y valor, y que el ejercicio del pensamiento y la propia acción humana individual o colectiva nada pueden hacer para modificar tal destino. Meillassoux y Gabriel se rebelan, cada uno a su modo, contra ese desatino.

En lo que sigue expondré primero los antecedentes generales de nuestra temática en el siglo XX, es decir, los planteamientos más significativos de antropología filosófica dados en ese siglo. En un segundo momento expondré el contexto de las corrientes ontológico-realistas de nuestro siglo, y en dos sucesivos subapartados daré cuenta respectivamente de las concepciones antropológicas de Markus Gabriel y Quentin Meillassoux. En un tercer apartado intentaré elaborar una síntesis de ambas concepciones como base para proponer una «nueva antropología filosófica» y un nuevo concepto de ser humano, de humanidad y de humanismo.

\section{LAS DISPUTAS DE LA ANTROPOLOGÍA FILOSÓFICA EN EL SIGLO XX}

Aunque la reflexión filosófica sobre el ser humano existe desde los orígenes de la filosofía (Buber 1949), no es hasta el siglo XX que se asume como una disciplina filosófica específica (Sobrevilla 2006), con Max Scheler (Scheler 1970), Helmuth Plessner, Arnold Gehlen (Gehlen 1980), Ernst Cassirer (Cassirer 1968), las escuelas neokantianas, y en un sentido a matizar, el existencialismo. No obstante, sabemos que el ser humano empezó a adquirir el carácter de centro o referente fundamental de la filosofía desde el Renacimiento y en los inicios de la Modernidad -con Descartes y su ego cogito, por ejemplo-. Pero es Kant quien incluye la pregunta ¿qué es el hombre? dentro de las cuatro interrogantes que el pensamiento filosófico debe responder (las otras tres son: ¿qué puedo conocer?, ¿qué debo hacer?, ¿qué puedo esperar? $\left.{ }^{3}\right)$; es Kant, pues, quien eleva la "antropología» al nivel filosófico (Kant 1978). A partir de él, el siglo XIX estuvo centrado en explayar la revelación de la positividad del ser humano y hacerlo el tema y objeto de las ciencias sociales y la filosofía. Según Michel Foucault, la episteme moderna (a diferencia de lo que él llama la «episteme clásica» de los siglos XVII-XVIII) es la episteme antropológica ${ }^{4}$. Como sabemos, el estudioso francés concluye su memorable libro Las palabras y las cosas con el anuncio escandaloso de

3 Las famosas preguntas kantianas aparecen en el curso de lógica del filósofo alemán: Kant 2010.

4 Foucault 1968, cap. IX. El hombre y sus dobles, p. 295 y ss.

Contrastes vol. XXVI-Nº1 (2021) 
la «muerte del hombre» como objeto privilegiado del saber -tesis que se extrae de los supuestos epistemológicos del estructuralismo (Lévi-Strauss, Lacan, la lingüística, Althusser). Es innecesario aclarar que Foucault, a pesar de cierto pesimismo que trasluce su pensamiento, no hablaba de la muerte física o real del ser humano. El estructuralismo defendió un «antihumanismo epistemológico», que tenía un carácter más bien polémico contra las posturas del humanismo existencialista, particularmente de Jean-Paul Sartre y sus seguidores. Pero la discusión entre humanismo y antihumanismo tiene antecedentes significativos en la filosofía del siglo XX: el famoso encuentro de Davos entre Ernst Cassirer y Martin Heidegger en 1929, y la polémica soterrada entre Heidegger y Jean-Paul Sartre a fines de la década de los 40. Lo comentaremos en seguida porque nos ofrecen un signo claro del estado de la cuestión antropológico-filosófica en el siglo pasado.

El encuentro de Davos, Suiza, ocurrido en marzo de 1929, tenía por objetivo fomentar la reconciliación entre Alemania y Francia, después de los estragos de la Primera guerra -el tema del encuentro era precisamente: ¿Qué es el hombre? Aunque participaron varios pensadores franceses importantes, no participó quien era en ese momento la figura más reconocida de la filosofía francesa, Henri Bergson. Quizá por esta razón, y curiosamente, el encuentro más llamativo y del que se guarda memoria es el que se da entre dos figuras principales -y contrapuestas- de la filosofía alemana: el neokantiano Ernst Cassirer, judío alemán, y el fenomenólogo Martin Heidegger, posteriormente vinculado al nazismo. Dos personalidades y dos estilos distintos de hacer filosofía. Aun así, por su común raíz kantiana, ambos pensadores guardan algunas coincidencias, aunque en aquel evento resaltaron más sus diferencias. Para varios autores (entre ellos: Carvajal 2007, Gordon 2012, Eilenberger 2019) el encuentro (o desencuentro o encontronazo) Cassirer-Heidegger marcó a la filosofía del siglo XX, en la medida en que se dieron cita ahí dos posiciones que definirían a la posteridad: la de Cassirer, más cercana al racionalismo y al positivismo liberal, y la de Heidegger, identificada con una posición antiracionalista y «romántica» (esto es, anti-moderna ${ }^{5}$ ). El tema del debate fue la disímbola interpretación que cada uno de estos pensadores hacía de la filosofía de Kant y su legado. Heidegger había defendido desde antes una rara lectura de Kant, en la que concebía la Crítica de la razón pura no como «teoría del conocimiento»-la interpretación estándar-sino como el primer planteamiento de la heideggeriana «ontología fundamental» (Heidegger 1954). Para el autor de El ser y el tiempo, Kant no construye una teoría del sujeto cognoscente sino

5 Sobre la crítica a Heidegger como referente de la posmodernidad, cf. Habermas 1989, Apartado 6. Heidegger: Socavación del racionalismo occidental en términos de crítica de la metafísica, pp. 163-196. 
una ontología de la finitud humana, cuyo carácter destacable es su receptividad frente al Ser (la realidad fenoménica en Kant). Esta posición dependiente del ser humano es un signo característico de la filosofía heideggeriana, condición de una ontología general (algunos podrían ver en ese carácter una explicación de las simpatías del desconcertado Heidegger con el régimen totalitario nazi).

Heidegger valoraba la reconstrucción del kantismo en términos de filosofía de la cultura hecha por Cassirer, su Filosofia de las formas simbólicas (Cassirer 1971), pero juzga que ese enfoque podía quedarse sin un fundamento de validez sino ubicaba su base ontológica. Por su parte, gran conocedor de la filosofía kantiana, Cassirer valora y entiende bien la interpretación heideggeriana de Kant, aunque considera que la insistencia de Heidegger en la finitud del sujeto humano es parcial, pues esa finitud solo tiene que ver con la actitud cognoscitiva (en la que somos receptivos de lo que Naturaleza nos da) pero no con la actitud moral, es decir con el Kant de la segunda crítica (Crítica de la razón práctica). En la dimensión ética-dimensión por excelencia de la razón, de la libertad y de lo universal (la ley moral)- el ser humano supera su pura finitud, accede a la espontaneidad y se acerca a lo infinito, a lo absoluto (Cassirer 1948; Cassirer 1947). El relativismo historicista que se desprende de la reflexión heideggeriana es insostenible.

Heidegger y Cassirer comparten, pues, un interés por el ser humano, aunque lo ven cada uno desde lados opuestos. Desde la perspectiva de su capacidad racional y práctica en Cassirer, o desde la perspectiva de su angustiosa facticidad existencial en Heidegger. Durante el siglo XX se asumió que el indudable «triunfador» de aquella disputa fue Heidegger, pero en la perspectiva de este siglo XXI quizá eso no sea ya tan obvio, y la figura de Cassirer -con toda su formalidad y seriedad y con ese estilo teórico imperturbable (nada que ver con los destellos de ciertas formulaciones de Heidegger)- deba ser recuperada, particularmente su idea de que el ser humano no está encerrado en una finitud ontológica sino que es capaz de abrirse a una dimensión de infinitud (moral, pero más allá de Cassirer, también ontológica). En verdad, como sostendremos al final de este ensayo, la oposición entre antropología y ontología debe superarse en un nuevo pensamiento filosófico capaz de pensar la relación entre el «Ser» y el «ser humano» desde su diferencia irreductible y desde la contingencia de su encuentro, preservando para el ser humano un rasgo irreductible de espiritualidad, aunque bajo un nuevo concepto de «espíritu».

Como decíamos, en la década del 40 del siglo pasado, Heidegger y Sartre mantuvieron una polémica indirecta, expuesta en sendos libros: del segundo: El existencialismo es un humanismo, de 1946, y como respuesta al anterior, Carta sobre el humanismo de Heidegger, de 1947. El texto de Sartre fue escrito (primero fue una conferencia) en respuesta a las críticas 
que posturas conservadoras dirigían a su filosofía al tacharla de irracionalista, pesimista, inhumana, etcétera. El reconocido pensador francés sostiene que el existencialismo aboga por una concepción del ser humano como ser libre; pero en cuanto ser situado, su libertad total conlleva igual responsabilidad: al elegir cada cual, al optar yo por algo, elijo por toda la humanidad. «Eligiéndome, elijo al hombre» (Sartre 2009, p. 35). El existencialismo no es un puro individualismo. El existente no es un ser aislado y fuera del mundo. Se encuentra intrínsecamente comprometido con los demás. Por su parte, Heidegger se niega a ser encasillado en el existencialismo (aunque su filosofía proporciona las bases de esta corriente filosófica) y abjura del humanismo. Su argumentación tiene un carácter ontológico: para él el ser humano -el Dasein, el «ser-ahí», en sus términos- tiene como función revelar al Ser, dar lugar al espacio del advenimiento ontológico. Lo que importa es el Ser y no el hombre. Ante el Ser, lo mejor para el hombre es callar: «antes de hablar, el hombre debe dejarse interpelar de nuevo por el ser, con el peligro de que, bajo ese reclamo, él tenga pocas o raras veces algo que decir» (Heidegger 2000, p. 20). El anti-humanismo heideggeriano (del cual el estructuralismo posterior, que hemos referido antes, resulta solo una variante superficial) es un antecedente de la crítica al antropocentrismo por parte del nuevo realismo y su interés por la ontología. No obstante, la concepción heideggeriana del ser humano como ente dependiente resulta al fin problemática: ¿en qué se diferencia finalmente del cuestionado objetivismo del pensamiento científico y su determinismo materialista y naturalista que hace del ser humano un ente dependiente de una Naturaleza o una materia previas? Por el contrario, la concepción sartreana de la libertad como rasgo irreductible del ser humano (Sartre 1972 p. 537 y ss.) no ha perdido vigencia y empieza a ser recuperada -junto con el existencialismo francés en general- por el pensamiento contemporáneo.

\section{EL NUEVO REALISMO: UNA FILOSOFÍA PARA NUESTRO TIEMPO}

En lo que va de este nuevo siglo han surgido diversos planteamientos que abogan por reponer una perspectiva realista en el pensamiento filosófico. Desde fines del siglo XX y lo que va de este siglo, se ha venido configurando un pensamiento que aboga por un retorno a lo real, y por recuperar una comprensión (más o menos) racional en contra del subjetivismo, idealismo y antropocentrismo de la filosofía moderna, pero también en contra del cientificismo, es decir, la creencia de que la ciencia es la única forma de pensamiento racional sobre la realidad -aunque no se trata de convalidar posturas anticientíficas sino solamente de dar su justo lugar al saber científico ${ }^{6}$.

6 Para una crítica del realismo especulativo y el nuevo realismo desde una perspectiva realista, pero epistemológicamente contextualista y no ontológica, cf. Benoist 2016. 
Concepciones no antropocéntricas, o que se plantean abrir una dimensión más allá de lo humano, las encontramos desde las filosofías de Nietzsche y Bergson, pasando por Whitehead y el propio Heidegger, hasta llegar a Gilles Deleuze (Ramírez \& Ralón 2017). Como antecedente del nuevo realismo, cabe mencionar al sociólogo y filósofo francés Bruno Latour, quien postula una ontología de las relaciones y las conexiones en un plano horizontal, es decir, más allá de las diferenciaciones clásicas humano/no-humano, natural/ cultural, ciencia natural/ciencia social, seres reales/seres de ficción, etcétera. Todo está interconectado, todo tiene que ver con todo; el Ser es una red y cualquier ente puede ser un actor o actante -Latour ha llamado a su teoría TAR, teoría del actor red (Latour 2008). Esta perspectiva de investigación da origen a lo que se llama ontología plana, esto es, una ontología en la que todos los seres se encuentran en un mismo nivel, sin jerarquías ni privilegios.

Otros autores, bajo perspectivas distintas, han desarrollado ontologías no antropocéntricas o no humanistas, tales como el materialismo ontológico de Manuel DeLanda (2011), la ontología nihilista de Ray Brassier (2017) o bien la ontología orientada a objetos (OOO) de Graham Harman -los dos últimos pertenecen ya propiamente al movimiento del realismo especulativo o nuevo realismo que inicia en 2007 (Ramírez 2016). Harman propone una ontología del objeto donde el sujeto humano no aparece ya como punto de referencia privilegiado (Harman 2016). Todo es objeto; existe una pluralidad indefinida de objetos, a distintos niveles y en distintas dimensiones; hay objetos individuales y objetos colectivos (un hormiguero, una tormenta, una epidemia son objetos). Más que simplemente desechar el componente subjetivo, Harman lo incorpora al campo ontológico: todo objeto tiene una cara intencional, una intencionalidad, en cuanto apunta a otros objetos o en cuanto es aprehendido por otros objetos (de alguna manera, la llama del encendedor percibe al cigarrillo y este a aquel). La intencionalidad no es privilegio de la conciencia humana, como en la fenomenología husserliana. Hay una especie de «polipsiquismo» ontológico. Ahora bien, estas posturas mantienen cierto nivel de coherencia a condición de elidir la interrogación reflexiva o meta-reflexiva acerca del sujeto que las elabora (los sujetos mismos Bruno Latour o Graham Harman). El pretendido objetivismo de estas posturas ontológicas comete el mismo error que todo objetivismo -teológico, metafísico o cientificista-: no se plantean la pregunta por la posibilidad de su teoría (¿se le puede aplicar a la teoría sociológica de la ciencia de Latour su propia teoría?, esto no llevaría a un relativismo incontrolable, a un regressus ad infinitum). Recogiendo planteamientos del pensamiento ecologista, de la ética animal y de cierto holismo más o menos metafísico, muy populares en las últimas décadas, la ontología plana considera que son igualmente reales los seres humanos, los virus, las crisis financieras, los gatos, los átomos, las 
moléculas, el metro atiborrado, etcétera (la ontología plana pareció hecha para entender un fenómeno como la pandemia de la covid-19). No obstante, en contra de lo que ha caracterizado al pensamiento filosófico desde sus orígenes, la ontología plana es incapaz de proponer un plan para la acción humana -una ética y una política- con una justificación racional de algún tipo. No hay nada que podamos hacer. El Ser nos apabulla.

En este sentido, considero que las figuras más relevantes del nuevo realismo - por no suscribir posturas contradictorias- son el alemán Markus Gabriel y el francés Quentin Meillassoux. Aunque sus teorías filosóficas, sus propuestas de realismo, son muy distintas entre sí, ambos coinciden en que conciben al ser humano como un ser que se separa o puede separarse del orden ontológico general, es decir, que posee -aun como posibilidad-ciertos rasgos propios, incomparables con ningún otro ser. Hay, pues, una diferencia ontológica entre el Ser en general y el Ser humano. Ahora bien, cada uno de estos pensadores comprende esa diferencia de un modo distinto, poniendo el acento en un rasgo o en otro. En seguida, daremos cuenta de las concepciones antropológicas de estos autores en el marco de una explicación breve y general de sus teorías filosóficas, centradas particularmente en sus propuestas de ontología.

\section{El NEOEXISTENCIALISMo de MarkuS Gabriel}

Markus Gabriel ha llamado la atención por su precocidad como académico y por su interés en combinar las dos funciones de un filósofo: el trabajo teórico riguroso, compenetrado con la tradición intelectual, y la actividad de divulgación, esto es, la decisión de comunicarse con un público más amplio, tomando como interlocutor, de la alguna manera, a la humanidad entera. Con esta decisión ha publicado algunos libros que se han convertido en best sellers, aunque se trata de textos que no son necesariamente de fácil lectura, en cuanto requieren la comprensión del marco teórico que los sustenta para calar en el alcance de los planteamientos expuestos. Gabriel parte, como el resto de los nuevos realistas, de la necesidad de reestablecer la ontología como disciplina básica de la filosofía, esto es, de afirmar, en contra de la tradición moderna, que podemos, sin prevenciones limitantes, tener acceso a la realidad como tal (Gabriel 2019a). A diferencia de otros neorrealistas, no reniega del valor de la epistemología (Gabriel 2020) lo que hace es -en un gesto parecido al de Harman- ontologizarla, es decir, incorporar la relación sujeto-objeto al campo de lo real. Rechaza, así, el presupuesto de la filosofía reflexiva de que el sujeto cognoscente es un ente fuera de la realidad. De esta manera, en cuanto el sujeto es parte de la realidad es insostenible cualquier forma de subjetivismo, pero también, y por la misma razón, cualquier forma de monismo: no hay una forma única de ser de la realidad. 
Gabriel sostiene el pluralismo ontológico como tesis filosófica fundamental (Gabriel 2017). Ahora bien, pluralismo no significa (o no básicamente) que existe una pluralidad indeterminada de entes, eventualmente totalizable. No existe el mundo, reza la proposición ontológica básica de Gabriel; no existe la totalidad de todos los entes. Pluralismo significa que lo que existe son campos de sentido, estructuras que delimitan conjuntos de entes según propiedades o relaciones características (Gabriel 2016). Los campos de sentido son indefinidos e ilimitados. Existe el campo de sentido de los instrumentos musicales que tiene relación con el de las notas musicales o el de la música sinfónica, o bien existe el campo de sentido de moléculas de la vida, o el de las partículas subatómicas, o el de la literatura de la revolución mexicana o el de la saga War Stars. Los entes individuales solo tienen sentido, solo existen, en cuanto aparecen en un campo de sentido, aunque cada ente puede aparecer a la vez en múltiples y quizá ilimitados campos de sentido (Beethoven puede aparecer en el campo de sentido de la música sinfónica pero también en el de los músicos alemanes). De esta concepción, Gabriel deriva las siguientes tesis ontológicas: a) no existe un campo de sentido privilegiado al que los otros pudieran reducirse -por ejemplo, el campo de sentido de la física-; b) hay campos de sentido que dependen de la actividad humana -como la saga War Stars o la literatura de la Revolución Mexicana-, pero hay otros que existen independientemente de que existan o no seres humanos -el campo de las partículas subatómicas, la galaxia EGS-zs8--; y c) una «visión-sin-mundo» elimina cualquier posibilidad de metafísica -la suposición de que se puede hacer una teoría del «mundo», de la totalidad de todo-y, por ende, cualquier forma de determinismo, teológico, materialista, naturalista u holístico. No existe, pues, un campo de sentido de todos los campos de sentido; el supuesto de Latour de la interrelación generalizada es una ficción. Las relaciones están circunscritas a campos determinados y no es cierto que cualquier cosa esté relacionada con cualquier otra o con todas las cosas que existen (dado que no existe el todo). Sobre la base de esta concepción ontológica podemos acercarnos a los postulados antropológicos de Gabriel.

Uno de los objetivos polémicos principales del filósofo alemán es la suposición reduccionista que acompaña al pensamiento científico moderno, esto es, la pretensión de llegar a explicar todas las formas de la realidad por la realidad física. En particular, Gabriel cuestiona radicalmente la suposición de que es posible reducir la mente al cerebro, o establecer una identidad entre mente y cerebro. Esta no es, para él, una tesis científica sino una creencia errónea, en la medida en que no está sustentada en ningún hecho sino solo en asunciones metafísicas e ideológicas. Gabriel llama «neurocentrismo»a la ideología pseudocientífica que insiste en que «yo soy mi cerebro» (Gabriel 2016a). Para él, en verdad, la mente -el yo, la conciencia, el espíritu- es 
irreductible a nada distinto de sí misma, en realidad, es irreductible a nada que «exista». El espíritu -el Geist- no es ninguna clase natural, es decir, ninguna cosa que pueda ser objeto de un estudio científico, ni ahora ni nunca (Gabriel 2019). Para Gabriel las clases naturales son aquellas cosas que existen independientemente de los conceptos que las designan -los loros existen independientemente de los conceptos zoológicos que los clasifican-, mientras que la mente es aquello que no existe independientemente de los conceptos que la designan: lo que soy o hago -escribir este artículo, preocuparme por las víctimas que está dejando la pandemia de coronavirus, escuchar los parloteos del loro del vecino- se modifica por el simple hecho de que lo piense. Pienso mis pensamientos y esto los cambia; pienso que pienso mis pensamientos (puedo seguir al infinito) y esto los cambia más. Esta es «la paradoja de la autoconciencia» (Gabriel 2019b). Pues el espíritu -y esto es lo propio del ser humano- no es nada sino la manera como él se define, sino la «imagen»o «idea» que él se hace de sí mismo. La autodefinición o autodeterminación es la cualidad propia de la mente y, por ende, del ser humano. La manera como nos concebimos, la imagen que nos hacemos de nosotros mismos, es lo que determina lo que somos y cómo actuamos.

Gabriel distingue entre la imagen individual y la imagen genérica. Cada individuo formula su propia teoría antropológica, pero hay una teoría antropológica genérica, para todos, aunque esta ha variado a lo largo de la historia. Nos hemos concebido como productos de las divinidades, o como obra suprema de un Dios único, o como efectos de procesos naturales y de las leyes de la naturaleza, o bien de procesos económico-sociales, o de los mecanismos neurobiológicos de nuestro cerebro, etcétera. Pero todas éstas son imágenes o ideas, no «hechos»; dependen de la manera como los pensamos. Ahora bien, todos los ejemplos mencionados coinciden en que asumen que existe una realidad previa y general - una totalidad, un todo del mundo o del Ser-al cual se adscribe el ser humano. En esos casos, la mente es irreflexiva; esto es, no reflexiona acerca de sí misma y no asume su capacidad autoformadora. Para Markus Gabriel la capacidad básica y general de la mente es la de formarse imágenes de sí misma, cualquier que esta sea. Una especie de meta-antropología - una antropología filosófica, precisamente- nos permite reconocer que, en tanto capaz de autodeterminarse a través de imágenes de sí mismo, el ser humano es un ser esencialmente (¿absolutamente?) libre.

La libertad es la condición humana: de ahí el nombre que Gabriel usa para designar su teoría: «neoexistencialismo», pues se trata de recuperar la tesis del existencialismo de Sartre. Ciertamente, Gabriel acepta que la mente no puede operar sin el sustrato físico-biológico, está condicionada, aunque no determinada por él. Sin embargo, no detalla las mediaciones corporales, sociales, históricas, etcétera, que condicionan también el tipo de imágenes 
que podemos formamos (aunque sí afirma que las humanidades son nuestra única «ciencia de la mente» posible y válida). ${ }^{7}$ Pero si bien tenemos la libertad de formarnos cualquier imagen, nos formamos al fin una imagen concreta, considerando nuestra situación real y nuestras posibilidades efectivas. Este argumento suplementario sería congruente con el existencialismo en todas sus variantes, incluyendo, por ejemplo, el existencialismo fenomenológico de Maurice Merleau-Ponty, quien proponía más que un concepto de la «mente condicionada», una idea del ser humano como una totalidad biológicoespiritual, o corporal-mental, o, más bien, al espíritu como la potencia de reintegración o reestructuración, de transfiguración o transformación de todas sus condiciones previas - materiales, biológicas, sociales, culturales- para llevarlas a un estadio de significación y espiritualidad superiores (MerleauPonty 1957 y 1973, Ramírez 2012).

\section{Dignidad ESPIRITUAL E INMORTALIDAD. El SOBRE-HUMANISMO DE Quentin MeILlassoux.}

El filósofo francés Quentin Meillassoux (nacido en 1967) presenta desde su tesis de doctorado L'Inexistence divine (de 1997, inédita), su propuesta de «materialismo especulativo», su ontología de la contingencia y su reflexión sobre la condición humana -que llama «ética factual»-. En 2006 publicó Après la finitud. Essai sur la necesité de la contingence (Meillassoux 2015), libro en el que expone su filosofía polemizando con el pensamiento moderno y posmoderno. Aquí aparece uno de sus conceptos más reconocidos, el de correlacionismo, con el que caracteriza el equívoco del pensamiento moderno desde Kant, esto es, la tesis de que solamente tenemos acceso a la correlación sujeto-objeto, que solo conocemos «fenómenos» y no a las cosas en sí mismas (la «cosa en sí»). Frente a esta tesis, Meillassoux pugna por una filosofía especulativa que vuelve a confiar en la capacidad de nuestra razón para comprender el mundo. Ahora bien, eso es posible solo a condición de que abandonemos, junto con el correlacionismo y el subjetivismo, toda metafísica, esto es, la suposición de que hay algo necesario en la existencia-Meillassoux cuestiona el imperio del principio de razón suficiente y del principio de causalidad-. La existencia es contingente y necesariamente contingente, esto es, la contingencia no es una «modalidad» existencial al modo clásico sino el carácter esencial de todo lo existente: «ser» $y$ «ser contingente» son lo mismo. El ente contingente es lo único que existe. Esto significa que el único principio

7 Se ha señalado la ausencia de una ética en el nuevo realismo. Al momento de la redacción de este ensayo, Markus Gabriel anunció, el 15 de abril de 2020, la aparición de su libro Moralischer Fortschritt in dunklen Zeiten. Universale werte für das 21 jahrhundert (Progreso moral en tiempos oscuros. Valores universales para el siglo 21). 
ontológico que podemos estatuir es, así lo llama Meillassoux, el principio de irrazón, o principio de factualidad: la no contingencia de la contingencia. Este principio implica que todo puede cambiar, que todo es posible. No hay determinismo absoluto, ni en la realidad como tal ni en la propia realidad humana. Aun las leyes de la naturaleza no son absolutas - puesto que no hay una Ley de leyes- y pueden dar un giro imprevisible; al menos, no hay ningún argumento en contra de esta posibilidad, ninguna garantía absoluta de que el orden natural sea inmodificable (Meillassoux 2020). La ontología de Meillassoux es una ontología del «puede ser», del devenir total y de la capacidad innovadora radical de la existencia.

Al desechar el principio de razón suficiente, Meillassoux asume un inmanentismo radical: la existencia es aquello que se explica por sí mismo, no hay una razón o una causa fuera de la propia existencia que de cuenta de ella. «Afirmamos que el inmanentismo, sostenido en su plena radicalidad, implica un mundo que no tiene nada fuera de él que pueda limitar su potencia de novedad» (1997, p. 11; nuestra traducción). La inmanencia radical -nada hay fuera de lo que existe- lleva a la asunción de que pertenece a esa existencia la potencia de novedad extrema (absoluta), es decir, a convalidar desde un punto de vista no teológico la idea de surgimiento exnihilo, de emergentismo: el universo emerge sin causa ni razón, y las sucesivas formas de existencia -materia, vida, conciencia- surgen también desde la nada, o son verdaderos saltos creadores en el Ser -milagros ontológicos- (Meillassoux 2007). No hay razón ni causa de que exista una cosa u otra, de que surja tal realidad o tal otra, no hay creación ni teleología en el universo. El entero Ser es un sinsentido. En la filosofía de Meillassoux no hay teocentrismo ni antropocentrismo. Todo está sometido a la contingencia, todo puede desaparecer o todo puede volver a aparecer sin ninguna razón. ¿Qué lugar puede haber para el ser humano en esta ontología extrema?

Uno fundamental. El valor del pensamiento especulativo estriba en que a través de él el ser humano capta la verdad eterna y absoluta de lo existente: que es contingencia pura, sin razón ni necesidad. Aprehender esa verdad y soportarla, no arredrarse frente a ella: en eso consiste la dignidad suprema del ser humano. En palabras de Meillassoux: «el hombre, porque él sabe lo eterno, adquiere valor. Pero el hombre no adquiere su valor del objeto de su conocimiento, es decir, de lo eterno mismo: no es lo eterno lo que es el valor, pues lo eterno no es más que la contingencia ciega, estúpida y anónima de todas las cosas. El valor es el del saber mismo: el hombre vale no por lo que él sabe sino porque él sabe» (Meillassoux 1996, p. 317). A diferencia de Heidegger, el naturalismo o la tradición metafísico-teológica, el objeto pensado no es superior al pensamiento que lo piensa, al pensador. Es en el pensar mismo, en la capacidad de pensar, que el ser humano encuentra su 
destinación incomparable, su designio supremo, el sentido de su vida; así conjura el sinsentido de la pura existencia material o biológica y da cuenta de cuál es la tarea a la que estaba destinado. ¿Pero poder pensar la indiferente y absurda contingencia de lo que existe es todo para el ser humano?

Aparece aquí la tesis quizá más escandalosa de Meillassoux. El espíritu no puede ser el momento último de la existencia, debe haber un momento más. El filósofo francés habla de la posibilidad de un cuarto Mundo, más allá de los Mundos de la materia, la vida y el espíritu que conocemos hasta ahora. Sería el mundo «divinológico», el mundo de la vida inmortal; de la inmortalidad como anhelo infinito de la vida, de la vida que, nietzscheanamente, se ama y afirma a sí misma y no quiere otra cosa que su «eterno retorno». ¿Es posible ese cuarto mundo? Precisamente, en la medida que la ontología de la contingencia de Meillassoux sostiene que todo es posible, no puede negar la posibilidad del advenimiento de lo «divino», de Dios -un «Dios» que ya no tiene cara de necesidad, que no es el «creador» del mundo, respecto al cual el mundo sería siempre «menos» que él, bajo el supuesto metafísicoteológico de que siempre habrá más realidad y perfección en la causa que en el efecto. Por el contrario, bajo el inmanentismo radical es posible que el efecto alcance un nivel imprevisible de realidad y ser más perfecto que su causa; en verdad, el universo solo puede ser valorado como potencia de innovación si renunciamos a la idea del Dios creador. Meillassoux sostiene la «inmanencia del otro mundo» (Meillassoux 2009), la posibilidad radical de que el otro mundo de las religiones surja en este mismo mundo, de que la fe se vuelva, como quería Deleuze, fe en este mundo y en ningún otro. Inmortalidad y divinidad aquí, en este mundo que, sin embargo, será otro mundo sin dejar de ser este mismo. Pero ¿cuál es la justificación del deseo de inmortalidad, de un cuarto mundo?

La respuesta la encontramos en la llamada «ética factual», la ética de la divina contingencia de Meillassoux (1996, p. 286 y ss.). ¿Qué cosa se nos aparece como imposible sin más en el mundo actual, en el tercer mundo, y que requeriría perentoriamente la posibilidad de un «cuarto mundo»? Hay muchas cosas que nos los parecerían así: volar como las águilas, vivir en las profundidades de los océanos, viajar en el tiempo, que existan sirenas y unicornios, etcétera, pero solo hay algo que parece absolutamente imposible y que sin embargo resulta absolutamente deseable: la justicia plena para todos los humanos, para vivos y muertos, esto es, la resurrección de los cuerpos y el advenimiento del reino del amor, «el cielo en la tierra». Meillassoux no tiene empacho en recuperar el contenido escatológico del pensamiento religioso -particularmente del cristianismo- para plantear la cuestión que ningún religioso se ha atrevido a plantear nunca: el cumplimiento del mensaje de salvación y el advenimiento de lo divino en este mundo. A diferencia de 
toda religión, el reino de lo «divino» no se encuentra en un ultramundo y sometido al arbitrio de un Dios existente que no sabe o no quiere -con toda su omnipotencia y omnisciencia- eliminar el mal del mundo, la muerte y la injusticia. Al Dios existente de las religiones Meillassoux opone el Dios virtual de una ontología de la contingencia. A diferencia del mero ateísmo que sigue aceptando el principio metafísico de la necesidad, ahora trasladado a la Naturaleza-, Meillassoux afirma: Dios no existe... todavía. No existe, pero puede llegar a existir (Meillassoux 2016).

¿Tiene sentido esta irreligión -así llama Meillassoux a su propuesta-, esta escatología especulativa? ¿Esta esperanza absoluta que pretende, no obstante, tener un fundamento racional? Según el principio de la ontología de la contingencia lo divino no es imposible, aunque no necesariamente se va a dar. No obstante, eso es suficiente para modificar nuestra conducta actual. Al menos, el nihilismo extremo no es irrefutable. No estamos determinados en lo absoluto. Nuestra libertad es concomitante de la propia «libertad» de lo existente: el determinismo es inoperante en todos los planos del Ser. Ahora bien, este indeterminismo puede conducir a un desvanecimiento de la vida, a la indiferencia y al nihilismo, o bien puede dar lugar a una conciencia humana animada, confiada verdaderamente en las posibilidades de la existencia. El ser humano no solo revela su dignidad superior como ser pensante, sino que el propio movimiento del pensamiento lo lleva a vislumbrar posibilidades positivas de su actuar, a mantener una esperanza que nos abre a la figura de una nueva condición humana, de un nuevo modo de ser humano. Es a lo que llamamos no poshumanismo o superhumanismo sino sobre-humanismo, en el sentido en que, incluso en Nietzsche, el más allá de lo humano es algo distinto de lo humano (pues el humano es por esencia nihilista, suponía Nietzsche), aunque ese nuevo ser tendrá que irse revelando, preparando a través de nosotros y de nuestro actuar comprometido. El ser humano es un puente, decía Nietzsche. «Lo que en el hombre se puede amar es que es un tránsito y no un ocaso» (Nietzsche 1997, p. 38).

\section{Nuevo CONCEPTO DE SER HUMANO. HuMANISMO POR VENIR}

¿Es posible un nuevo concepto de ser humano, una nueva idea de lo humano? La respuesta positiva a esta pregunta nos permitiría plantear el sentido de un nuevo humanismo. Creemos que las perspectivas filosóficas de Meillassoux y Gabriel nos dan la pauta para una renovada antropología filosófica. Y más allá de ellos, diversos pensadores de la historia de la filosofía pueden venir en nuestro auxilio. En seguida detallaremos nuestra propuesta. Primeramente, describimos y criticamos de manera general la concepción tradicional y todavía actual del ser humano como un ser sometido a algún tipo de determinismo. Después, y como conclusión general de este ensayo, 
puntualizaremos los elementos que un nuevo concepto de ser humano debe contener y significar.

Desde sus orígenes, el ser humano se ha preguntado acerca de sí mismo: ¿qué soy? ¿Por qué existo? Quizá fue este cuestionamiento lo que dio origen a la conciencia (la autoconciencia) y al homo sapiens sapiens como tal. La urgencia de esta pregunta, acompañada con cierto desconcierto o angustia existencial, llevó al ser humano (nos llevó, nos lleva todavía, a cada uno y a todos) a buscar las respuestas en alguna cosa distinta de él, capaz de dar cuenta -aunque sea de forma apresurada o superficial- de su por qué y su para qué. Esta imagen de nosotros mismos como un ser predeterminado o sobredeterminado por una instancia exterior, general y omniabarcante ha tenido distintos contenidos a lo largo de la historia, particularmente desde la aparición de formas culturales complejas y sistemas de pensamiento más o menos consistentes -mitologías, religiones, cosmovisiones, ideologías, etcétera. Nos hemos concebido como creaturas de divinidades o de una sola divinidad única y absoluta, o bien como productos de estructuras socioculturales cerradas, totalitarias. Por otra parte, al insistir en establecer una esencia humana -animal racional, alma inmortal, sustancia pensante-, abstracta e inamovible, el pensamiento metafísico ha contribuido a reforzar las diversas formas de determinismo, todas las cuales tienen en verdad un carácter ideológico (formas de pensamiento no racionales al servicio de estructuras de poder). De hecho, a toda ideología le subyace una metafísica, y la metafísica posee en última instancia un carácter ideológico.

En la modernidad, con los avances del conocimiento científico-natural, surge la idea, más o menos atea, de entender al ser humano como un mero producto de la naturaleza y de unas leyes que lo someten y definen. El naturalismo es la fórmula más conocida, y supuestamente evidente, del determinismo, pero de éste conocemos otras variantes, varios momentos o versiones -es como una insistencia que no se da por vencida-, pero todas consisten en el intento de «explicar» lo propio de lo humano por una realidad previamente existente. El determinismo se apoya normalmente en algún tipo de saber científico, pero llevando sus resultados más allá de lo estrictamente autorizado por los procesos del conocimiento científico: esto es lo que se llama cientificismo. Como contexto general, me permito proponer a continuación una lista de las principales variantes de determinismo cientificista.

a.- El fisicalismo, que se plantea explicar por los componentes últimos de la materia y las leyes de la física toda realidad, incluida la realidad humana -somos al fin de cuentas un sistema de partículas subatómicas moviéndose conforme a tales o cuales regularidades probabilísticas.

b.- El biologicismo, según el cual los seres humanos somos el resultado de procesos evolutivos, condicionados por nuestra carga genética y sometidos a las leyes de la supervivencia que rigen todo el reino de los seres vivos. 
c.- El historicismo y otras variantes derivadas de las ciencias sociales y humanas -sociologismo, psicologismo, estructuralismo lingüístico y cultural-que aceptan someterse a los supuestos y procedimientos objetivistas y deterministas de la ciencia natural. Todas esas posturas asumen que el ser humano está subsumido en órdenes simbólicos, funcionales o ideológicos que limitan las posibilidades de su pensamiento y el alcance de su libertad.

d.- El neurologismo - «neurocentrismo» le llama Markus Gabriel-, que pretende explicar las operaciones mentales superiores -el pensamiento, la conciencia- mediante el análisis del funcionamiento del cerebro y del sistema nervioso en general. Una consecuencia de esta postura es el llamado «poshumanismo», que bajo el supuesto de que existe identidad entre la inteligencia artificial y la inteligencia humana considera que la primera terminará en algún momento por absorber a la segunda (el ciborg). Para esta concepción, lo esencial de la mente es la inteligencia computacional, y los aspectos fenoménico-sensibles, afectivos y axiológicos de la experiencia humana-los propiamente humanos-son irrelevantes o desechables.

e.- El ecologismo, variante reciente del biologicismo, que insiste, más allá de los postulados válidos, no ideológicos, de la ciencia ecológica, en que el ser humano es un ser vivo al mismo nivel que los demás y cuyo comportamiento es más bien dañino para el resto de las especies. Una variante de estas posturas es el reciente pensamiento animalista, que insiste en hablar de animales humanos y animales no humanos, aplanando o desvalorando cualquier particularidad o preeminencia de lo humano - lo cual lleva a la contradicción de a la vez llamar a una «responsabilidad» de los humanos ante las demás especies, lo que claramente supone asumir una diferencia entre el humano y el animal.

En el campo filosófico, ciertas propuestas teóricamente ambiguas, como la ontología heideggeriana o la ontología de procesos u ontología plana, que hemos referido antes, parecieran sucumbir al determinismo, aunque lo que se ponga ahora como entidad determinante sea una «comprensión receptiva del Ser» o un holismo de relaciones que sobrepasa nuestras capacidades y posibilidades de comprensión y acción; en fin, se trata de posturas que rechazan conceder cualquier privilegio al ser humano, bajo el pretexto de los equívocos a que nos han sometido las ideologías humanistas. Ciertamente, el esencialismo humanista es cuestionable, pero de esto no se sigue que haya que proscribir cualquier forma de humanismo posible.

De esta manera, arribamos a la propuesta de un nuevo concepto de ser humano. Insistiríamos primero en la radical diferencia ontológica entre la realidad o las diversas formas de realidad y el ser, la realidad o la condición humana. No somos entes u objetos como cualesquier otros. Nuestra existencia es una extrañeza, una singularidad en el orden de lo existente. Una característica humana fundamental es que no podemos definirnos en términos de una especie 
(como las especies animales), donde los individuos son solamente variantes de una estructura o molde general que define las mismas características para todos sus miembros. Cierto que, como seres vivos, como entes biológicos operamos bajo ese esquema. Pero no solamente. El ser humano es indistintamente singular y universal a la vez. Cada humano, en su singularidad infinita, porta en sí a la humanidad, es la humanidad. La feminista italiana Patrizia Violi recurrió al concepto de «infinito singular» para dar cuenta de la condición femenina, buscando escapar tanto del esencialismo universalista (patriarcal) como del diferencialismo sustancialista, que niega la posibilidad de una humanidad común (Violi 1991). Este enfoque puede ser generalizado a todo lo humano. El carácter singular y universal a la vez es la condición que funda el sentido ético de nuestra vida: no nos podemos concebir como ajenos a la idea de una humanidad genérica, a los otros - mujeres o varones-, y a todos los otros habidos y por haber. En esta condición se asienta el imperativo categórico kantiano. Como explica Markus Gabriel, los seres humanos somos autónomos no en cuanto meros individuos particulares (con tales y cuales intereses y deseos) sino solo en cuanto nos sometemos a la ley moral, que tiene carácter universal, la misma para todos los humanos. «Lo que nos vuelve humanos, a ti y a mí, es algo que precisamente no me distingue de ti. La humanidad es algo esencialmente compartido» (Gabriel 2018, p. 63). Es nuestra autocomprensión como humanos genéricos lo que nos convierte a todos en seres espirituales, esto es, en seres capaces de comprensión universal, y universalmente válida y verdadera. Es necesario, pues, recuperar el «espiritualismo» de las grandes figuras del idealismo clásico -Kant, Hegel, Fichte-aunque teniendo en cuenta todas las transfiguraciones del pensamiento filosófico en los últimos dos siglos (marxismo, vitalismo, pragmatismo, fenomenología, existencialismo, teoría crítica).

El ser humano es, pues, un ser espiritual libre. Libres, en cuanto que, como argumenta Markus Gabriel, tenemos la capacidad como mentes o espíritus de determinarnos a nosotros mismos, de darnos una imagen o una idea de lo que somos y debemos ser. En este sentido podemos rechazar todo sustancialismo y esencialismo sobre el ser humano; como bien decía el existencialismo: la conciencia no es una entidad, es un no-ser, un movimiento o un devenir. Ahora bien, la concepción de la libertad de Gabriel (y la de Sartre) resulta insuficiente, o meramente abstracta o absolutista, sino preguntamos por la relación de nuestra libertad con la verdad y el sentido -con el valor, con los valores(Taylor 2019). Aquí necesitamos un concepto de espíritu más preciso, que incluye la capacidad humana para comprender la realidad (el Ser, la existencia, etcétera), esto es, nuestra capacidad de pensamiento ontológico. La propuesta de Meillassoux viene a ayudarnos para alcanzar una comprensión más concreta del ser humano. La libertad de nuestro pensamiento (del pensamiento 
especulativo) nos permite asumir la contingencia de toda existencia y nos abre a una realidad llena de posibilidades, donde el ideal ético de justicia y todos los valores superiores -igualdad, libertad, autonomía, verdad, belleza- pueden ser recuperados como orientaciones incuestionables de la vida y la acción humana, en cuanto un pensamiento ontológico liberado de toda metafísica de la totalidad o de la necesidad- nos permite suponer que, dado que nada es imposible en el devenir contingente de lo existente, podemos asumir que los ideales éticos no sean meras ficciones o construcciones humanas y puedan ser realizados efectivamente en este mundo. Esta creencia, esta esperanza, esta prerrogativa humana para esperar lo inesperable, lo «imposible posible», es el rasgo que da sentido a nuestra libertad y que define la suprema espiritualidad del ser humano. Con lo que, creemos, estaría de acuerdo Cassirer.

De alguna forma nos hemos quedado solamente en el planteamiento del problema y todavía habría muchos puntos que precisar y ampliar. Nos conformarnos con haber abierto una tarea que deba ser continuada.

\section{REFERENCIAS BIBLIOGRÁFICAS}

BENOIST, J. 2016: «Realismo sin metafísica». Cuadernos salamantinos de filosofia, 43, pp. 213-236.

BRASSIER, R. 2018: «Desnivelación: 'contra las ontologías planas'», Reflexiones marginales, 44. En internet (consultado el 14-04-2020): https://revista. reflexionesmarginales.com/desnivelacion-contra-las-ontologias-planas/

BRASSIER, R. 2017: Nihil desencadenado. Ilustración y extinción. Madrid: Materia oscura.

BRYANT, L.R. 2011: The Democracy of Objects. Ann Arbor: Open University Press. BUBER, M. 1949: ¿Qué es el hombre? México: Fondo de Cultura Económica.

CARVAJAL, J. 2007: «Finitud radical y moralidad a la luz del debate HeideggerCassirer sobre el kantismo», Fragmentos de filosofia, 5, pp. 239-262.

CASSIRER, E. 1971: Filosofía de las formas simbólicas. México: Fondo de Cultura Económica.

CASSIRER, E. 1968: Antropología filosófica. Introducción a una filosofia de la cultura. México: Fondo de Cultura Económica.

CASSIRER, E. 1948: Kant: vida y doctrina. México: Fondo de Cultura Económica.

CASSIRER, E. 1946: El mito del Estado. México: Fondo de Cultura Económica.

DELANDA, M. 2016: Assemblage Theory. Edinburgh: Edinburgh University Press.

DELANDA, M. 2011: Mil años de historia no lineal. Barcelona: Gedisa.

ELLENBERGER, W. 2019: Tiempo de magos. La gran década de la filosofia. 19192019. Madrid: Taurus.

FERRARIS, M. 2013: Manifiesto del nuevo realismo. Madrid: Biblioteca nueva.

FOUCAULT, M. 1968: Las palabras y las cosas. México: Siglo XXI.

GABRIEL, M. 2020. The Limits of Epistemology. Cambridge: Polity Press.

GABRIEL, M. 2019: Neoexistencialismo. Concebir la mente humana tras el fracaso del naturalismo. Barcelona: Pasado y presente. 
GABRIEL, M. 2019a: El sentido del pensamiento. Barcelona: Pasado y presente.

GABRIEL, M. 2019b: «The paradox of self-consciousness», Edge (11-11-2019), consultado el 11/04/2020: https://www.edge.org/conversation/markus_gabrielthe-paradox-of-self-consciousness

GABRIEL, M. 2018: Le pouvoir de l'art. Paris: Saint-Simon.

GABRIEL, M. 2017: Sentido y existencia. Una ontología realista. Barcelona: Herder.

GABRIEL, M. 2016: Por qué el mundo no existe. México: Océano.

GABRIEL, M. 2016a: Yo no soy mi cerebro. Filosofía de la mente para el siglo XXI. Barcelona: Pasado y Presente.

GEHLEN, A. 1980: El hombre. Su naturaleza y su lugar en el mundo. Salamanca: Sígueme.

GORDON, P. 2012: Continental Divide. Heidegger, Cassirer, Davos. Cambridge: Harvard University Press.

HABERMAS, J. 1989: El discurso filosófico de la modernidad. Madrid: Taurus.

HARMAN, G. 2016: El objeto cuádruple. Una metafísica de las cosas después de Heidegger. Barcelona: Anthropos.

HEIDEGGER, M. 2000: Carta sobre el humanismo. Madrid: Alianza.

HEIDEGGER, M. 1954: Kant y el problema de la metafisica. México: Fondo de Cultura Económica.

KANT, E. 2010. Lógica. Buenos Aires: Corregidor.

KANT, E. 1978: Filosofía de la historia. México: Fondo de Cultura Económica.

LATOUR, B. 2008: Reensamblar lo social. Una introducción a la teoría del actorred. Buenos Aires: Manantial.

MEILlASSOUX, 2020. Metafísica y ficción extracientifica. Santiago de Chile: Roneo.

MEILLASSOUX, Q. 2016: «Duelo por venir. Dios por venir». En: Ramírez 2016, pp. 68-100.

MEILLASSOUX, Q. 2015: Después de la finitud. Ensayo sobre la necesidad de la contingencia. Buenos Aires: Caja negra.

MEILLASSOUX, Q. 2009: «L'Immanence d'outre Monde». Ethica, 16, 2, pp. 39-71.

MEILLASSOUX, Q. 2007: «Matérialisme et surgissement ex nihilo». MIR, pp. 52 69.

MEILLASSOUX, Q. 2006: Après la finitude. Essai sur la necessité de la contigence. Paris: Seuil.

MEILLASSOUX, Q. 1996: L'Inexistence divine. Tesis de doctorado en filosofía. Université de París I (en internet: accedido el 14-04-2020).

MERLEAU-PONTY, M. 1993: Fenomenología de la percepción. México: PlanetaAgostini.

MERLEAU-PONTY, M. 1957: La estructura del comportamiento. Bueno Aires: Hachette.

NIETZSCHE, F. 1997: Asi habló Zaratustra. Madrid: Alianza.

RAMÍREZ, M.T. y L. RALÓN. 2017: «Gilles Deleuze y el nuevo realismo». Avatares filosóficos, 4, pp. 19-33.

RAMÍREZ, M.T. (Coord.) 2016: El nuevo realismo. La filosofía del siglo XXI. México: Siglo XXI. 
RAMÍREZ, M.T. (Coord.) 2012: Merleau-Ponty viviente. Barcelona: Anthropos.

SARTRE, J.-P. 2009: El existencialismo es un humanismo. Barcelona: Edhasa.

SARTRE, J.-P. 1972: El ser y la nada. Ensayo de ontología fenomenológica. Buenos Aires: Losada.

SCHELER, M. 1970: El puesto del hombre en el cosmos. Buenos Aires: Losada.

SOBREVILLA, D. 2006: «El retorno de la antropología filosófica». Diánoia, LI, 56: pp. 95-124.

TAYLOR, CH. 2019: «La refutación de Gabriel», en Gabriel 2019: pp. 81-92.

VIOLI, P. 1991: El infinito singular. Madrid: Cátedra.

Mario TeOdoro Ramírez Cobián es Profesor Emérito de la Universidad Michoacana de San Nicolás de Hidalgo (México)

Líneas de Investigación:

Realismo especulativo, Fenomenología, Filosofía de la cultura, Estética

Publicaciones recientes:

(2021): «El nihilismo mexicano. Más allá de El hiperión», en g. Hurtado y J. A. Torres, Ensayos filosóficos sobre la Cuatra Transformación de México, México: Torres Asociados.

(2016): El nuevo realismo. La filosofía del siglo XXI. México: Siglo XXI.

Correo electrónico: marioteo.1956@gmail.com 